\title{
Managing the dominant follicle in high-producing dairy cows
}

\author{
MC Wiltbank ${ }^{1}, \mathrm{R}_{\text {Sartori }}^{2}$, JLM Vasconcelos ${ }^{3}, \mathrm{AB}$ Nascimento $^{1}, \mathrm{AH} \mathrm{Souza}^{4}$, \\ AP Cunha', A Gumen' ${ }^{5}$, S Sangsritavong ${ }^{6}$, JN Guenther ${ }^{1}, \mathrm{H} \mathrm{Lopez}^{7}$ and \\ JR Pursley ${ }^{8}$
}

\begin{abstract}
'Department of Dairy Science, University of Wisconsin-Madison, Madison, Wisconsin, USA; ${ }^{2}$ Department of Animal Science, USP, Piracicaba, São Paulo, Brazil; '³Department of Animal Production, UNESP, Botucatu, São Paulo, Brazil; "Accelerated Genetics, Baraboo, Wisconsin, USA; ${ }^{\text {s Department }}$ of Obstetrics and Cynecology, University of Uludag, Bursa, Turkey; ${ }^{6}$ Central Research Unit, 113 Thailand Science Park, Prathumthani, Thailand; 'American Breeders Service, DeForest, Wisconsin, USA; ${ }^{8}$ Department of Animal Sciences, Michigan State University, E. Lansing, Michigan, USA
\end{abstract}

Reduced reproductive efficiency has been reported in high-producing dairy cows. Sources of reproductive inefficiency include decreased expression of estrus, increased diameter of the ovulatory follicle and reduced fertility when cows are inseminated after estrus, increased incidence of double ovulation and twinning, and increased pregnancy loss. To overcome some of these inefficiencies, reproductive management programs have been developed that synchronize ovulation and enable effective timed artificial insemination (AI) of lactating dairy cows. Effective regulation of the corpus luteum $(\mathrm{CL})$, follicles, and hormonal environment are critical for optimizing these programs. Recent programs, such as the 5-day CIDR program, Double-Ovsynch, G-6-G, and estradiol benzoate-CIDR programs were designed to more effectively control one or more physiological events. These events include synchronization of a new follicular wave at the beginning of the program, optimization of the circulating progesterone (P4) concentrations and duration of follicular dominance, optimized reductions in $\mathrm{P} 4$ and increases in circulating estradiol (E2) concentrations during the preovulatory period, and tightly synchronized ovulation of a follicle of optimal size and fertility for implementation of timed Al. The success of these programs has been remarkable, although there is substantial variability in effectiveness due to environmental, management, nutritional, genetic, and disease factors as well as potential variability in some aspects of reproductive physiology among commercial dairy farms. Future programs will optimize the reproductive physiology while simplifying the protocol implementation and also match specific reproductive management protocols to specific farms and even specific cows (for example primiparous vs. multiparous). 


\section{Distinctive aspects of follicular growth in lactating dairy cows}

The high-producing dairy cow has unique physiology related to follicular growth that impacts applied aspects of reproductive management programs. Dynamics and regulation of follicular waves have been reviewed previously (Ginther et al. 1996b; Adams et al. 2008; Aerts \& Bols 2010). This review will focus on observations in lactating dairy cows that are relevant to reproductive management. Specific research citations will be used as examples to illustrate concepts. Due to space limitations, there will be no attempt to provide exhaustive literature citations or comparison of all important research studies during the discussion of each concept.

Follicular waves occur throughout pregnancy with each wave preceded by a surge in FSH. The magnitude of the FSH surge increased as pregnancy progressed. The maximum diameter of the dominant follicle, however, decreased as pregnancy progressed from $11.1 \mathrm{~mm}$ in Month 4 to $8.5 \mathrm{~mm}$ in Month 9 (Ginther et al. 1996b). Emergence of the final follicular wave during pregnancy occurred three weeks before parturition (Ginther et al. 1996b) whereas the interval from the last peak of FSH until parturition was approximately 12 days. Following parturition, there was a large increase in FSH with average FSH concentrations being 2-fold greater after parturition than average FSH surge concentrations during pregnancy. The interval from parturition to the day of emergence of the first follicular wave post-partum averaged 4 days (range of 2 to 7 days) (Ginther et al. 1996b).

Lactating dairy cows have variable intervals to first ovulation that depend on which post-partum follicular wave is ovulated. The dominant follicle from the first post-partum follicular wave has three potential outcomes: ovulation, atresia, or to become a large anovular follicle such as a follicular cyst. For example, Savio et al. (1990) reported that $74 \%$ of lactating cows ovulated the dominant follicle of the first follicular wave whereas $21 \%$ became cystic. In contrast, Butler et al. (2006) reported that $31 \%$ of cows ovulated the first dominant follicle post-partum, whereas $44 \%$ of cows had atresia of the first wave dominant follicle. The formation of atretic follicles was associated with low circulating E2 concentrations. There were $25.4 \%$ of cows that had a large anovular follicle that either became cystic (15\%) or produced high E2 but did not ovulate (11\%). These two papers illustrate the variability (31\% vs. $74 \%$ ) between studies/herds in the fate of the first-wave dominant follicle. The prevailing LH pulse frequency during the dominance phase of the first follicular wave is likely the major driver for growth and E2 production by the dominant follicle. Insufficient LH causes an atretic first dominant follicle with inadequate E2 production (see Crowe, 2008). It is still not clear what physiological changes result in a large anovular follicle with high E2 production during the first post-partum follicular wave. The lack of an adequate $\mathrm{GnRH} / \mathrm{LH}$ surge in response to increased $\mathrm{E} 2$ may underlie the development of these large anovular follicles (Gumen \& Wiltbank 2002). Following the first follicular wave post-partum there continue to be follicular waves every 7 to 10 days with multiple potential outcomes such as ovulation, atresia, or cyst development, that depend on the physiological status of the cow.

There are a number of intriguing aspects of follicular wave dynamics that are unique to high production lactating dairy cows (Sartori et al. 2004). First, higher producing dairy cattle have lower circulating E2 concentrations than would be expected given their size of dominant follicles. For example, Lopez et al. (2005) reported decreasing peak circulating E2 concentrations with increasing milk production. Paradoxically lower circulating E2 was associated with greater follicular diameter when milk production increased. This contradiction could be due to reduced E2 production by the dominant follicle or increased E2 metabolism with increasing milk production in Idairy cows. The hypothesis that follicular E2 production varies with milk production has not yet been adequately tested. Greater E2 metabolism with increasing milk production, however, has been demonstrated (Sangsritavong et al. 2002). It seems likely that lesser circulating E2 in cows with greater follicular volume is primarily related to greater E2 
metabolism in high milk-producing cows (Lopez et al. 2005). Greater E2 metabolism is probably caused by greater blood flow through the gastrointestinal tract and liver associated with the greater feed intake that is required to maintain high milk production (Wiltbank et al. 2006).

There also appears to be decreased expression of estrus in dairy cattle (Lopez et al. 2004). Lesser expression and detection of estrus in lactating dairy cows may reduce reproductive efficiency in the highest producing cows. Timed Al programs allow high- and low-producing dairy cows to be inseminated at a similar efficiency. This aspect makes these programs particularly appealing for herds with high-producing cows, In addition, the time of Al can be optimized in relation to the time of ovulation. Programs based on the expression of estrus may have more variability in the interval from Al to ovulation. A third intriguing aspect of follicular development in lactating dairy cows is that there is an increasing size of the ovulatory follicle with increasing milk production when cows are inseminated to estrus (Wiltbank et al. 2006). These differences may be reduced with timed $\mathrm{Al}$ programs because $\mathrm{GnRH}$ (or other agent) is used to induce ovulation before expression of estrus (discussed below). When cows are inseminated to estrus there may be a delay in ovulation in the highest-producing cows because greater E2 metabolism delays the attainment of sufficient circulating E2 to induce the $\mathrm{GnRH} / \mathrm{LH}$ surge. Ovulation of larger follicles in higher producing dairy cows may partially explain the reduction in fertility in cows inseminated to estrus (Santos et al. 2010).

A fourth intriguing aspect of lactating dairy cows is the large percentage of cows that are anovular. Surprisingly, there is generally no relationship detected between level of milk production and the percentage of anovular cows. The follicular dynamics and physiology underlying different types of anovulation in cattle have been reviewed (Wiltbank et al. 2002; Wiltbank et al. 2008a). The most common type of anovular lactating dairy cow ( $\sim 60 \%$ of anovular dairy cows) had follicles larger than ovulatory size but smaller than the classically defined cystic size (Wiltbank et al. 2002; Gumen et al. 2003). Anovular cows of this type probably have hypothalamic resistance to the positive feedback effects of E2 (Wiltbank et al. 2002; Gumen \& Wiltbank 2005). The timed Al programs discussed below generally will induce ovulation in this type of anovular cow as well as most other types of anovular dairy cows (Wiltbank et al. 2008a). Nevertheless, cows that are anovular or have low P4 (proestrous period) at the start of the Ovsynch program have lower fertility than ovular cows with elevated P4 at start of the Ovsynch program (Bisinotto et al. 2010a).

A fifth intriguing aspect of follicular development in lactating dairy cows is an increase in double ovulation associated with greater milk production (Lopez et al. 2005). A comparison of the hormonal concentrations during the first follicular wave in cows that select a single follicle compared with cows that select two or three dominant follicles has been performed (Lopez et al. 2005). The main hormonal differences between cows with single vs. multiple dominant follicles are increased circulating FSH and LH during the $24 \mathrm{~h}$ before follicular deviation (largest follicle $\geq 8.5 \mathrm{~mm}$ ). A reduction in circulating E2 does not appear to be the underlying cause of selection of multiple follicles. Circulating E2 is actually greater in cows with two or three dominant follicles than in cows with one dominant follicle during this critical period before deviation. A reduction in circulating P4 during this period may partially explain the increases in $\mathrm{FSH}$ and $\mathrm{LH}$ and increased selection of co-dominant follicles (see below). Differences in other aspects of reproductive physiology in lactating dairy cows have also been reported, including number and dynamics of follicular waves, CL volume, circulating P4, and reproductive diseases (Thatcher et al. 2010). The reader is referred to the many other reviews on related topics such as follicular management of anovular cows, patterns of follicular waves and fertility, and nutritional effects on follicular development and fertility in dairy cattle (Thatcher et al. 2002; Macmillan et al. 2003; Bilby et al. 2006; Leroy et al. 2008a; Leroy et al. 2008b; Wiltbank et al. 2008a). 


\section{Management of the follicle for timed AI in lactating dairy cows}

Synchronized ovulation combined with timed AI has been a goal of reproductive physiologists for many years (Wiltbank et al. 1965; Zimbelman \& Smith 1966; Odde 1990; Pursley et al. 1995; Thatcher et al. 1996; Lauderdale 2009). Obtaining good fertility with timed Al programs requires optimization of at least 5 distinct aspects of reproductive physiology (Fig. 1). First, synchronization of the follicular wave that will produce the dominant follicle for ovulation near the timed AI. Second, optimization of the hormonal environment and length of time during growth of this synchronized follicular wave. Third, optimization of the preovulatory period including synchronized regression of the CL with optimized timing in the reduction in circulating P4 and increases in circulating E2. Fourth, synchronization of ovulation of a dominant follicle with a high fertility oocyte, optimal periovulatory hormonal environment, and optimal timing and placement of high fertility semen in relation to the synchronized ovulation. Fifth, development of an optimal hormonal environment after Al that allows pregnancy establishment and maintenance. All of these physiological aspects of the program, together with management, nutritional, genetic, and disease aspects of the cow and herd, will contribute to the ultimate outcomes from these programs.

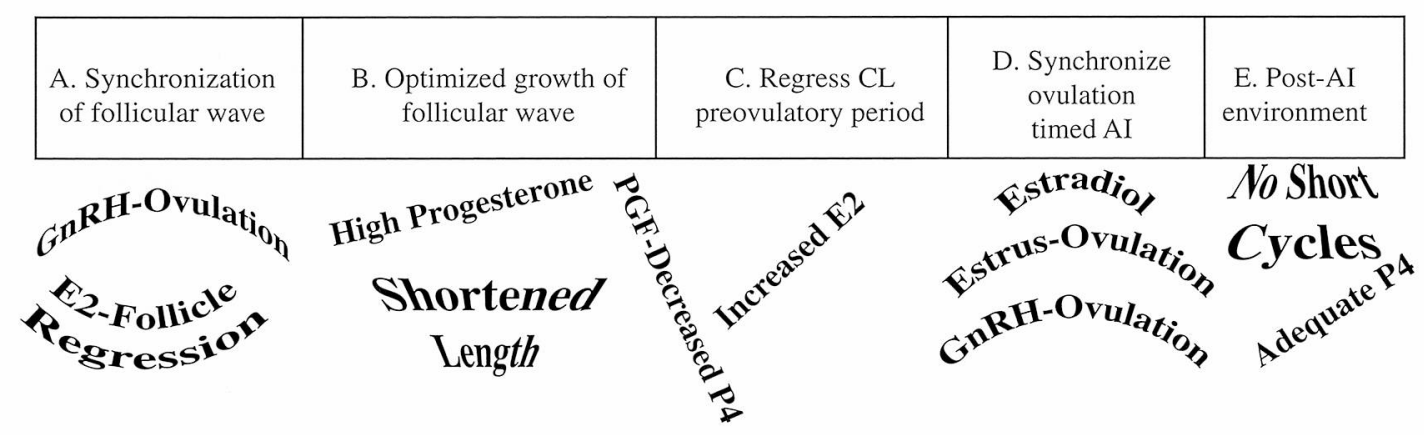

Fig. 1. Schematic of characteristic processes and current methods for timed Al programs.

\section{Initiation of a synchronized follicular wave}

One of the major changes with modern reproductive management protocols is the focus on controlling follicular development in addition to control of CL function and circulating P4 concentrations. Detailed studies of the follicular development during synchronization protocols became practical with the development of commercially-available transrectal ultrasound systems. Early ultrasound studies of bovine ovaries clearly showed the dynamics of follicular growth in cows that included follicular waves emerging every 7 to10 days (Savio et al. 1988; Sirois \& Fortune 1988; Knopf et al. 1989). During emergence of a follicular wave, multiple follicles begin growing with the eventual deviation of a single dominant follicle (normally) from this cohort of follicles (Ginther et al. 1996a). The size of the follicle at deviation in Holstein dairy cattle averages about $8.5 \mathrm{~mm}$ and is associated with a nadir in circulating FSH concentrations. Continued growth of the dominant follicle is dependent on LH secretion. Ovulation depends on the LH surge. The maximal size of the dominant follicle during the estrous cycle or pregnancy and the timing of loss of function of the dominant follicle (i.e., turnover) depend on the hormonal environment and particularly circulating LH concentrations.

Synchronization of a new follicular wave generally entails removal of the functional dominant follicle either by physical destruction, hormonally-induced ovulation, or hormonal inhibition of gonadotropins so that the follicle regresses (Bodensteiner et al. 1996). Following aspiration 
of the dominant follicle there is a rapid increase in circulating FSH caused by the removal of follicle-derived inhibitors of FSH secretion. This FSH "surge" is followed by emergence of a new follicular wave, usually within 1 day. Similarly, induction of ovulation of the dominant follicle either with LH or hCG is followed by an FSH surge and emergence of a new follicular wave. From a practical standpoint, removal of the dominant follicle is usually performed by ovulation of the follicle using GnRH treatment (Thatcher et al. 1993; Pursley et al. 1995). Treatment with $\mathrm{GnRH}$ induces an $\mathrm{LH}$ and FSH surge that peaks within $2 \mathrm{~h}$ after treatment and returns to nadir concentrations by about $4 \mathrm{~h}$. If this gonadotropin surge causes ovulation then there is a surge in FSH that peaks at about $24 \mathrm{~h}$ after the initial $\mathrm{GnRH}$ treatment with coincident emergence of a new follicular wave (Bodensteiner et al. 1996). Each of these follicular synchronization methods is primarily effective when the dominant follicle is removed, in other words in cows that ovulate in response to GnRH or gonadotropin treatments. Treatment of dairy cows at random stages of the estrous cycle with $\mathrm{GnRH}$ results in ovulation in only 50 to $70 \%$ of the cows (Pursley et al. 1995; Galvao \& Santos 2010). Different stages of the estrous cycle have different ovulatory responses with the greatest response on Days 5 to 9 and reduced response earlier and later in the estrous cycle (Vasconcelos et al. 1999; Moreira et al. 2000; Bello et al. 2006). It is unrealistic, therefore, to expect $100 \%$ synchronization of follicular waves by using $\mathrm{GnRH}$ alone at the beginning of a synchronized ovulation program. Although ovulation to the initial $\mathrm{GnRH}$ is not necessarily a requirement for conception with these programs, there is generally a reduction in fertility in cows that do not ovulate to the initial GnRH treatment (Thatcher et al. 2002; Galvao \& Santos 2010).

One of the methods that is used to increase ovulation to the first GnRH treatment during Ovsynch is to control the day of the cycle at the initiation of Ovsynch. Generally, the best day to give the first $\mathrm{GnRH}$ treatment is Day 6 or 7 of the cycle when there is a large dominant follicle (Vasconcelos et al. 1999; Moreira et al. 2000; Bello et al. 2006). There is a high ovulation rate after GnRH on Day 6 or 7 and therefore a synchronized emergence of the new follicular wave. This is one of the key ideas underlying the development of Presynch-Ovsynch (Moreira et al. 2001; Ei-Zarkouny et al. 2004), G-6-G (Bello et al. 2006), and Double-Ovsynch (Souza et al. 2008). During Double-Ovsynch, for example, the first Ovsynch protocol synchronizes the cows so that the second Ovsynch procedure is initiated on Day 7 of the cycle.

An alternative method for removing the functional dominant follicle involves inhibiting the gonadotropins that are necessary to sustain dominance. From a practical stand-point this can be accomplished with E2 treatment in the presence of high P4 (Bo et al. 1995; Burke et al. 2003). It is necessary to have $\mathrm{P} 4$ present during $\mathrm{E} 2$ treatment to prevent an $\mathrm{E} 2$-induced $\mathrm{LH}$ surge and ovulation. The combination of $\mathrm{E} 2$ and $\mathrm{P} 4$ decreases $\mathrm{LH}$ and $\mathrm{FSH}$ and this reduction in gonadotropin support results in follicular atresia and the regression of dominant follicles within $36 \mathrm{~h}$ after treatment (Burke et al. 2003; Martinez et al. 2005). After treating Holstein cows with $2 \mathrm{mg}$ of E2-benzoate with or without injectable P4 in a CIDR protocol, circulating $\mathrm{FSH}$ and $\mathrm{LH}$ reached nadir concentrations by $\sim 0.5$ days; a time that corresponded with peak circulating E2. The FSH surge occurred at 3 to $4 \mathrm{~d}$ after the initial E2 treatments (Cavalieri et al. 2003). The length of time from hormonal treatment to emergence of the new follicular wave has been shown to be independent of the stage of follicular development at E2 treatment (Kim et al. 2007a). It does depend, however, on the type (Martinez et al. 2005) and dose (Burke et al. 2003; Colazo et al. 2005) of E2 that is used for treatment. The circulating E2 profiles for different esters of E2 are different in cattle (Martinez et al. 2005; Souza et al. 2005). Although long half-life estrogens (e.g., E2-cypionate) have been successfully used to synchronize the emergence of follicular waves in beef cattle and heifers (Colazo et al. 2005), they seem to be less precise for synchronizing wave emergence when used in lactating dairy cows (Thundathil et al. 1998) perhaps because of the rapid E2 clearance rates in the liver of high milk-producing 
cows. The time to emergence of the new follicular wave is reduced with increasing milk production (Souza et al. 2009). For example, treatment of cows with $2 \mathrm{mg}$ of E2-benzoate results in follicular wave emergence at $3.8 \mathrm{~d}$ in the highest-producing cows but not until $4.5 \mathrm{~d}$ in the lowest-producing cows.

Collectively, E2 + P4 protocols will induce synchronous follicular wave emergence in about 70 to $90 \%$ of cattle. Most failures in synchronization are related to lack of dominant follicle regression and late wave emergence (Diskin et al. 2002; Souza et al. 2009). One of the key benefits of synchronizing the follicular wave by inhibiting follicular growth (compared with ovulating the dominant follicle) is that a new $\mathrm{CL}$ is not present during the synchronization protocol. This makes incomplete luteal regression less likely in the $\mathrm{E} 2+\mathrm{P} 4$ protocol compared with the Ovsynch-like protocols (Kim et al. 2007b). A downside of not inducing a new ovulation at the beginning of the synchronization procedures is that circulating P4 could be lower in $\mathrm{E} 2+\mathrm{P} 4$ protocols than needed for optimal oocyte quality in timed Al protocols (Kim et al. 2007b; Rutigliano et al. 2008).

\section{Optimizing growth of the follicular wave}

It is important to optimize the "fertility" of the follicle that will ovulate the oocyte for subsequent fertilization and embryonic development. This optimization involves ovulation of an "optimized" oocyte with production of an "optimized" CL to maintain embryo development and pregnancy. These may be conflicting goals since ovulation of a larger follicle will likely result in a larger $\mathrm{CL}$ with greater $\mathrm{P} 4$ production. The oocyte from a larger follicle, however, may have reduced fertility (Ahmad et al. 1995; Ahmad et al. 1996; Revah \& Butler 1996). The hormonal environment and duration of growth of this follicle have been found to be key components in optimizing fertility in timed Al programs. Hormonal environment and duration of the follicular wave may impact fertility through its effects on oocyte function, granulosa/thecal cell number or function, oviductal or uterine function, and other potential reproductive functions.

The circulating P4 concentrations have been found to have substantial impact on subsequent fertility. A relationship between pre-AI P4 concentration and subsequent fertility was documented almost 3 decades ago where first service conception rate increased by approximately $10 \%$ for every $1 \mathrm{ng} / \mathrm{ml}$ increase in average P4 (Fonseca et al. 1983). A study in seasonal dairy herds in New Zealand tested this hypothesis as well (Xu et al. 1997). Cows were synchronized with prostaglandin F2 $\alpha$ (PGF) 13 d apart and supplemented or not supplemented with a CIDR for $5 \mathrm{~d}$ before the second PGF to increase circulating P4 before Al. There was an increase in percentage of cows that showed estrus after the second PGF (89.6\% vs. $82.9 \%$ ) and percentage pregnant to $\mathrm{Al}(\mathrm{P} / \mathrm{Al})$ after this estrus $(65.1 \%$ vs. $59.7 \%)$. Analysis of the stage of the estrous cycle at the time of the second PGF demonstrated that the CIDR improved fertility in cows in the earlier (Days 5 to $9 ; 52.3 \%$ vs. $64.8 \% \mathrm{P} / \mathrm{Al}$ ) and mid-cycle (Days 10 to $13 ; 59.3 \%$ vs. $66.2 \%$ ) but not later cycle (Days 14 to $19 ; 71.3 \%$ vs. $71.4 \%$ ). Increasing P4 in cows with lower P4 before PGF synchronization, therefore, improved fertility at the subsequent AI. Indeed, many of the pre-synchronization programs, such as Presynch-Ovsynch, may improve fertility through their effects on $\mathrm{P} 4$ during the pre-Al period.

We tested whether P4 concentrations during growth of the preovulatory follicle would alter double ovulation rates (DOV) and fertility in lactating cows (Cunha \& Wiltbank, unpublished). Holstein cows $(n=624)$ were presynchronized before the breeding Ovsynch with an Ovsynch72 protocol (GnRH-7d-PGF-3d-GnRH) but timed Al was not performed (Fig. 2). Cows then began Ovsynch immediately (the 2 nd GnRH of the Ovsynch 72 was the 1 st GnRH of the breeding Ovsynch) (Low-P4; Short Double-Ovsynch) or cows received the first GnRH of the 
breeding Ovsynch 1 week later (High-P4; Double-Ovsynch; Fig. 2). Ovarian ultrasound and blood sampling were performed in order to assess ovulation, pregnancy status, and circulating P4 concentrations. As expected, cows in the High-P4 group had greater P4 concentrations than cows in the Low-P4 group at the first GnRH of the breeding Ovsynch $(1.80 \mathrm{ng} / \mathrm{mL}$ vs. $0.38 \mathrm{ng} /$ $\mathrm{mL})$ and at the PGF $(4.43 \mathrm{ng} / \mathrm{mL}$ vs. $2.51 \mathrm{ng} / \mathrm{mL})$. The DOV was greater in the Low-P4 than in the High-P4 group (20.6\% vs. $7.0 \% ; \mathrm{P}=0.03)$. A previous study also reported a reduction in DOV in cows with increased pre-AI P4 concentrations (Rutigliano et al. 2008). Overall P/AI at Day 29 was greater in the High-P4 compared with the Low-P4 group $(51.0 \%, n=292$ vs. $37.1 \%, \mathrm{n}=272 ; \mathrm{P}=0.001$ ). Surprisingly, pregnancy loss (between Day 29 to 57 ) was also less in the High-P4 than the Low-P4 group (6.8\% vs. $14.3 \%$; $\mathrm{P}=0.05)$. High-P4 during follicular development, therefore, reduced selection of co-dominant follicles and DOV. In spite of ovulating fewer follicles and in spite of a lower P4 concentration after AI, cows treated with the High-P4 protocol had better fertility than those treated with the Low-P4 protocol. These data provide strong evidence for the importance of high P4 during Ovsynch.

A. Double-Ovsynch - High P4 during follicle growth.

\begin{tabular}{|c|c|c|c|c|c|c|}
\hline Sun & Mon & Tues & Wednesday & Thursday & Friday & Sat \\
\hline & & & & & GnRH & \\
\hline & & & & & PGF & \\
\hline & GnRH & & & & & \\
\hline & GnRH & & & & & \\
\hline & PGF & & GnRH-PM & Al-AM & & \\
\hline
\end{tabular}

B. Short Double-Ovsynch - Low P4 during follicle growth.

\begin{tabular}{|c|c|c|c|c|c|c|}
\hline Sun & Mon & Tues & Wednesday & Thursday & Friday & Sat \\
\hline & & & & & GnRH & \\
\hline & & & & & PGF & \\
\hline & GnRH & & & & & \\
\hline & PGF & & GnRH-PM & Al-AM & & \\
\hline
\end{tabular}

Fig. 2. Diagrams of a typical weekly calendar for the protocols used in the experiment to test the effect of P4 concentration during the Ovsynch protocol (growth of ovulatory follicle) on fertility and double ovulation rate.

There are many potential physiological mechanisms that may underlie the effect of high P4 during follicular growth to reduce DOV, increase fertility, and reduce pregnancy loss in timed $\mathrm{Al}$ protocols. Greater circulating P4 decreases LH pulses (Stumpf et al. 1993). In previous studies, low P4 during follicular growth resulted in development of persistent, lower-fertility follicles (Ahmad et al. 1994; Ahmad et al. 1996; Revah \& Butler 1996). For example, lactating dairy cows had lower fertility after development of a persistent follicle compared with control dairy cows (44\% vs. 12\%; (Ahmad et al. 1996). A recent study (Cerri et al. 2009) flushed embryos from cows that started Ovsynch on Day 3 or Day 6 of the estrous cycle. Only $7.1 \%$ of cows that started Ovsynch on Day 3 ovulated to the first $\mathrm{GnRH}$, whereas $88.6 \%$ of cows ovulated to the first GnRH when Ovsynch was started on Day 6. Fertilization rate was similar for the two groups (85 vs. 86\%). The percentage of high quality embryos (Grades 1 and 2), however, was greater for cows that started Ovsynch on Day 6 (83.7\%) compared with Day 3 (47.0\%). 
The period of follicular dominance averaged $8.0 \mathrm{~d}$ in cows that started Ovsynch on Day 3 , and averaged $5.8 \mathrm{~d}$ for Day 6 cows. A $2 \mathrm{~d}$ increase in follicular dominance, therefore, reduced embryo quality ( $78 \%$ increase in degenerate embryos). In our experiment that used DoubleOvsynch with high or low P4 concentrations, the age of the follicles were identical in the two groups. The preovulatory follicle from the low P4 group, however, would have been exposed to a greater number of LH pulses and this could underlie the low fertility. Thus, reduced fertility can occur in cows that ovulate even minimally persistent follicles or in cows with follicles that may not be older but are overexposed to $\mathrm{LH}$. This may be a critical concept for fertility in normally-ovulating dairy cows or during synchronized breeding protocols.

In an attempt to reduce the duration of follicular dominance, a shortened Ovsynch strategy has been developed. The interval between GnRH and PGF was reduced from 7 to $5 \mathrm{~d}$ along with an increase in the proestrous period from 48 to $56 \mathrm{~h}$ (time of second GnRH) until $72 \mathrm{~h}$. This strategy has resulted in improved in fertility in beef cattle (Bridges et al. 2008). A similar strategy in dairy cattle produced encouraging results. Santos et al. (2010) reported an improvement in fertility in the 5-d compared with the 7-d Ovsynch protocol (5-d: 37.9\% vs. 7-d: 30.9\%). Two treatments with PGF were required, however, for optimizing the synchronization of cows assigned to the 5-d protocol. For the 5-d and the 7-d protocols, timing of the second GnRH and timed $\mathrm{Al}$ were both done at $72 \mathrm{~h}$ after the PGF (Cosynch-72). This timing of GnRH and Al has been found to reduce fertility in the 7-d protocol (Brusveen et al. 2008) but does not alter fertility in the 5-d protocol (Bisinotto et al. 2010b) compared with GnRH treatment at 56 $\mathrm{h}$ and $\mathrm{Al} 16 \mathrm{~h}$ later. Additional studies are necessary to evaluate the differences between these protocols and to optimize the protocols. It seems likely that protocols with reduced duration of follicular dominance, combined with a longer proestrous period (discussed below), can increase fertility in lactating dairy cows.

\section{Optimizing the hormonal environment during the preovulatory period}

The hormonal environment during the proestrous period is critical for reproductive success. First, lack of complete $\mathrm{CL}$ regression leads to elevated $\mathrm{P} 4$ during the proestrous period and reduced fertility during timed Al protocols (Souza et al. 2007). In one study we found that $15 \%$ of cows did not have complete CL regression following the Double-Ovsynch protocol. These cows had greatly reduced fertility to the timed Al (Brusveen et al. 2009). Treatment with a second injection of PGF, $24 \mathrm{~h}$ after the first, resulted in almost all cows having complete $\mathrm{CL}$ regression with a slight $(\sim 5 \%)$ but not significant improvement in fertility.

A second critical factor is to optimize E2 concentrations before AI. In cows treated with GnRH followed seven days later by PGF and then inseminated to estrus, treatment with $1 \mathrm{mg}$ of E2-cypionate at $24 \mathrm{~h}$ after PGF, increased E2 concentrations, and increased fertility to the estrus breeding (Cerri et al. 2004). To test the effect of E2 during an Ovsynch protocol, we treated cows with Ovsynch (GnRH - 7d - PGF - 56h - GnRH - 16h - timed Al) with or without treatment with $1 \mathrm{mg}$ of E2 (native estradiol-17ß) at $48 \mathrm{~h}$ after PGF ( $8 \mathrm{~h}$ before second $\mathrm{GnRH}$ treatment and $24 \mathrm{~h}$ before timed $\mathrm{Al}$ at $72 \mathrm{~h}$ ) (Souza et al. 2007). As expected, there was an increase in expression of estrus in cows treated with E2 (Ovsynch: $44.4 \%$ vs. Ovsynch + E2: $80.2 \%$ ); however, there was no overall improvement in fertility associated with E2 treatment (Ovsynch: $39.4 \%$ vs. Ovsynch +E2: $42.4 \%$ ). Treatment with E2 improved fertility in low body condition score (BCS $\leq 2.5$ ) cows (Ovsynch: $28.1 \%$ ys. Ovsynch + E2: $40.0 \%$ ) such that these cows had similar fertility to cows in high BCS (Ovsynch: $43.7 \%$ vs. Ovsynch +E2: $43.9 \%$ ). A sufficient E2 surge, therefore, may be the key rate-limiting step for obtaining high fertility in low BCS cows during timed Al protocols. Treatment with E2 also tended to increase fertility 
in cows ovulating medium-sized follicles $(15$ to $19 \mathrm{~mm}$ ) but not in cows ovulating smaller or larger follicles. This observation is consistent with the concept that increasing circulating E2 may be important for optimizing the preovulatory hormonal environment during timed Al protocols, at least in cows that ovulate an optimized follicle size. Thus, optimizing circulating E2, along with other follicular/luteal optimizations, may improve fertility in cows inseminated to estrus or in cows that are timed Al (Cerri et al. 2004; Souza et al. 2007).

A third factor to consider for improving fertility is increasing the length of the proestrous period. The importance of increasing the proestrous period has been demonstrated in beef cattle treated with the 5-day protocol (Bridges et al. 2010). It seems likely that changes in the proestrous period may alter fertility by affecting the uterine environment and (or) the follicle and oocyte.

\section{Synchronization of ovulation}

There are many reasons to synchronize ovulation and perform timed Al rather than wait for estrus. First, higher-producing lactating dairy cows demonstrate less estrous behavior than lower-producing cows (Lopez et al. 2004). Timed Al programs, therefore, should result in an increased percentage of higher-producing cows receiving Al compared with programs based on detection of estrus. Second, follicle size could be theoretically optimized during a synchronized ovulation program and this could improve fertility. Third, timing of Al can be optimized in relation to ovulation (one previously designated time in all cows) and this should increase management efficiency and fertility. The first advantage (increased percentage of cows receiving $\mathrm{Al}$ ) has been reported in direct comparisons of timed $\mathrm{Al}$ and estrus programs. Improvements in fertility, however, have not been a consistent result. A meta-analysis done in 2005 (71 trials in 53 research publications with sufficient experimental details for inclusion in the analysis) reported no significant differences in P/AI between Ovsynch compared with various other reproductive management strategies (Rabiee et al. 2005).

There are several methods to synchronize the time of ovulation. Any method that will synchronize estrus will also synchronize the time of ovulation; although, synchronization may not be sufficient to allow good success with timed AI. Most timed Al programs use either a $\mathrm{GnRH}$ or estradiol treatment to increase the synchrony of ovulation during these programs.

Treatment with GnRH results in an LH surge that reaches a peak by about $2 \mathrm{~h}$ and causes ovulation between 24 to $32 \mathrm{~h}$ after $\mathrm{GnRH}$ (Pursley et al. 1995). There are at least $10 \%$ of cows that do not ovulate to the second GnRH treatment of Ovsynch (Vasconcelos et al. 1999; Bello et al. 2006; Souza et al. 2007; Brusveen et al. 2009; Galvao \&v Santos 2010). Two primary reasons explain the lack of synchronized ovulation to the Ovsynch protocol. First, cows may come into estrus before the $\mathrm{GnRH}$ treatment and therefore ovulate prematurely because of an endogenous GnRH/LH surge (Vasconcelos et al. 1999). Premature ovulation during Ovsynch was only found in cows that started Ovsynch in the later estrous cycle ( $\geq$ Day 12) and did not ovulate to the first GnRH treatment of Ovsynch (Vasconcelos et al. 1999). Second, cows may not have a dominant follicle at the time of the second $\mathrm{GnRH}$ treatment due to initiation of a new follicular wave during the Ovsynch protocol. Immature follicular development at the second GnRH of Ovsynch was found in cows that initiated Ovsynch at various stages of the estrous cycle and in cows that may or may not have ovulated to the first GnRH of Ovsynch (Vasconcelos et al. 1999). Obviously, cows that do not ovulate to the second GnRH of Ovsynch have little or no fertility to the timed AI.

Cows that ovulate after Ovsynch may not ovulate an ideal size of follicle. For example, Souza et al. (2007) found that only $57.6 \%$ cows ovulated a follicle of 14 to $19 \mathrm{~mm}$ after Ovsynch. 
Twenty percent of cows ovulated a follicle that was too small $(\leq 13 \mathrm{~mm})$ and $22.5 \%$ ovulated a follicle that was too large ( $>20 \mathrm{~mm}$ ). Vasconcelos et al. (2001) used an aspiration to produce a new follicular wave mid-way through the Ovsynch protocol so that there was ovulation of smaller $(\sim 11.5 \mathrm{~mm})$ follicles at the second GnRH of Ovsynch compared with non-aspirated controls ( $\sim 14.5 \mathrm{~mm})$. The cows ovulating the small follicles had reduced fertility $(12 \% \mathrm{vs} .45 \%$ for control). The reduction in fertility in cows ovulating small follicles may be due to reduced E2 before $\mathrm{Al}$, ovulation of a less-mature oocyte, and/or reduced P4 after Al (due to ovulation of a smaller follicle with a subsequently smaller $\mathrm{CL}$ ). Ovulation of larger follicles may in some cases produce oocytes with reduced fertility (Ahmad et al. 1996; Cerri et al. 2009). Improvements in fertility to Ovsynch, therefore, are likely to be obtained by increasing the percentage of cows that ovulate an optimally-sized follicle after the final $\mathrm{GnRH}$ treatment.

Many studies have used different estrogens to synchronize the time of ovulation in dairy cows treated with E2+P4 or Ovsynch-like protocols. Estrogens are available for use in synchronization protocols in many countries but are not available in the United States or Europe. Estrogen products are generally sold at a lower price than $\mathrm{GnRH}$ products and therefore can be economically attractive for producers. Nevertheless, the increased estrous behavior caused by estrogens is negatively viewed by some producers because of the risk of accidents and the excessive activity observed in the estrogen-treated cows. Estrogens with shorter half-lives (E2 and E2-benzoate) are typically used 24 to $48 \mathrm{~h}$ after PGF treatment with $\mathrm{Al}$ at about $1 \mathrm{~d}$ after E2 treatment. Studies with the Heat-Synch protocol (Pancarci et al. 2002; Cerri et al. 2004; Stevenson et al. 2004) have substituted the longer-acting E2-cypionate $24 \mathrm{~h}$ after PGF treatment to synchronize the time of ovulation. Although time of ovulation is shorter after GnRH compared with E2-cypionate treatment, fertility was similar in Heat-Synch vs. Ovsynch protocols. The Heat-Synch protocol has been shown to improve fertility as compared with cows inseminated to estrus (Cerri et al. 2004). Interesting, there was improved fertility in cows that showed estrus during the Heat-Synch protocol, although expression of estrus had no effect on fertility in cows that were Al to Ovysnch (Pancarci et al. 2002). Some protocols have also used E2-cypionate at the time of PGF/CIDR removal with similar results as observed with synchronized ovulation after a GnRH treatment (Souza et al. 2009). Synchronized ovulation occurs around 70 to 75 $h$ after CIDR removal. Data from an earlier trial (Colazo et al. 2004) using beef heifers, however, indicated that better fertility is achieved when E2-cypionate was given $24 \mathrm{~h}$ after CIDR removal rather than at the time of CIDR removal. Thus, there are a variety of different options for synchronizing ovulation with estrogens. Optimal timing of treatments and of Al can vary based on the half-life of the estrogen, management factors, and the type of protocol used to synchronize follicular/luteal function before the synchronized ovulation.

\section{Post-AI treatments to regulate follicles}

Management of follicles after breeding can also be used to regulate reproduction and potentially improve the efficiency of reproductive management programs. Resynchronization of ovulation (Resynch) in cows that did not become pregnant to the first Al can improve reproductive management programs by reducing the time between AI. The physiological aspects of Resynch programs are similar to what has been discussed above; however, some management considerations are critical because of the need to definitively confirm non-pregnancy in cows before treatment with PGF (Galvao et al. 2007; Silva et al. 2007; Wiltbank et al. 2008b).

The use of hCG or GnRH after AI has been tested as a follicular/luteal management strategy to improve fertility in lactating dairy cows (De Rensis et al. 2010). Treatment of cattle with these agents at certain times of the cycle can result in ovulation of the dominant follicle. If a 
follicle is ovulated there should be increased circulating P4 due to the presence of an accessory CL. In addition, hCG could increase circulating P4 due to direct effects of hCG to stimulate luteal function; although, this theoretical hCG effect has not been confirmed experimentally in cattle. The increases in circulating P4 after treatment with hCG on Days 5 to 7 of the estrous cycle have been shown in many studies. For example, Santos et al. (2001) treated cows that had been Al to estrus with 3,300 IU of hCG on Day 5 after Al. Treatment with hCG increased circulating P4 and increased fertility (Control: 38.9\% vs. hCG: 45.8\%). Our recent studies following timed $\mathrm{Al}$ protocols found a smaller but significant effect of treatment on Day 5 with hCG on fertility (Control: $37.3 \%$ vs. hCG: $40.8 \%$ ) with significant hCG effects only in first lactation cows (Nascimento, Souza, Bender, Wiltbank, unpublished). Thus, it appears that hCG treatment on Day 5 improves fertility although the physiological reason for this improvement was not defined in these studies. One possibility is that the hCG-induced increase in circulating P4 improves fertility due to P4 effects on the uterus and (or) embryo. A number of studies are consistent with respect to increased P4 increasing embryonic development but the P4 effect appears to be mainly during the early luteal phase (Days 5 to 9) (Mann et al. 2006). Treatment with hCG on Day 5 does not increase circulating P4 until Day 8. Perhaps earlier increases in P4 would produce greater improvements in fertility. Another possible effect of hCG treatment is a change in follicular development pattern that could delay luteolysis and thus improve fertility. Ovulation on Day 5 results in a new follicular wave emerging by Day 6 and likely turnover of the dominant follicle of this wave before luteolysis. Thus, the cow is likely to have 3 rather than 2 follicular waves. This change in follicular wave patterns may improve fertility (Townson et al. 2002). For example, an absence of circulating E2 from a dominant follicle near the time of normal luteolysis will delay luteolysis until there is sufficient E2 to increase PGF secretion from the uterus (Araujo et al. 2009). Changes in follicular wave patterns and timing of luteolysis, therefore, may be part of the mechanism for increased fertility after hCG-induced ovulation of the dominant follicle of the first follicular wave.

\section{Closing remarks}

One of the biggest changes in reproductive management research during the last 2 decades has been a focus on precise regulation of follicular development. This was possible because of the availability of high-resolution ultrasound technology allowing evaluation of the dynamic processes of follicular emergence, selection, growth, atresia, and ovulation. Evaluation of the dynamics of follicular development in anovular conditions has provided much greater insight into the physiology of these processes (Wiltbank et al. 2002). An understanding of the natural processes regulating follicular development is allowing greater insight into how changes in patterns of follicular development as well as management and nutritional factors may be regulating fertility (Thatcher et al. 2002; Townson et al. 2002; Macmillan et al. 2003; Leroy et al. 2008a; Leroy et al. 2008b). The most revolutionary of the research changes after introduction of ultrasound may be the many variations of synchronization protocols that are focused on synchronized ovulation of an "optimized follicle". Initial programs resulted in fertility that was similar to breeding to estrus but offered the advantage of a timed AI of all cattle on a preselected day (Pursley et al. 1997). Recent, optimized synchronization strategies may result in better fertility in lactating dairy cows than breeding to estrus. Additional research is needed to evaluate these programs in various commercial and experimental conditions. For example, some of these programs may be best for cows in specific physiological circumstances as exemplified by the better conception rates in primiparous than multiparous cows following the Double-Ovsynch protocol (Souza et al. 2008). Clearly, a great deal of progress is being made 
in understanding the physiology of these programs with future progress needed to increase consistency, simplicity, and economic value of these programs for dairy producers.

\section{References}

Adams GP, Jaiswal R, Singh I \& Malhi P 2008 Progress in understanding ovarian follicular dynamics in cattle. Theriogenology $6972-80$.

Aerts JMJ \& Bols PE J 2010 Ovarian follicular dynamics. A review with emphasis on the bovine species. Part II: Antral development, exogenous influence and future prospects. Reprod Domest Anim 45 180-187.

Ahmad N, Beam SW, Butler WR, Deaver DR, Duby RT, Elder DR, Fortune JE, Griel LC, Jones LS, Milvae RA, Pate JL, Revah I, Schreiber DT, Townson DH, Tsang PC W \& Inskeep EK 1996 Relationship of fertility to patterns of ovarian follicular development and associated hormonal profiles in dairy cows and heifers. I Anim Sci 74 1943-1952.

Ahmad N, Schrick FN, Butcher RL \& Inskeep EK 1994 Fertilization rate and embryo development in relation to rersistent follicles and peripheral estradiol-17-beta in beef cows. Biol Reprod $\mathbf{5 0}$ 65-65.

Ahmad N, Schrick FN, Butcher RL \& Inskeep EK 1995 Effect of persistent follicles on early embryonic losses in beef cows. Biol Reprod 52 1129-1135.

Araujo RR, Ginther OJ, Ferreira IC, Palhao MM, Beg MA \& Wiltbank MC 2009 Role of follicular estradiol17 beta in timing of luteolysis in heifers. Biol Reprod 81 426-437.

Bello NM, Steibel JP \& Pursley JR 2006 Optimizing ovulation to first GnRH improved outcomes to each hormonal injection of Ovsynch in lactating dairy cows. I Dairy Sci 89 3413-3424.

Bilby TR, Block J, do Amaral BC, Sa O, Silvestre FT, Hansen PJ, Staples CR \& Thatcher WW 2006 Effects of dietary unsaturated fatty acids on oocyte quality and follicular development in lactating dairy cows in summer. J Dairy Sci 89 3891-3903.

Bisinotto RS, Chebel RC \& Santos JEP 2010a Follicular wave of the ovulatory follicle and not cyclic status influences fertility of dairy cows. I Dairy Sci 93 3578-3587.

Bisinotto RS, Ribeiro ES, Martins LT, Marsola RS, Greco LF, Risco CA, Thatcher WW \& Santos JEP 2010b Effect of moment of induced ovulation and progesterone (P4) for resynchronization on fertility of Holstein cows in a 5-d timed Al program. I Dairy Sci 93, E-Suppl, 1675.

Bo GA, Adams GP, Pierson RA \& Mapletoft RJ 1995 Exogenous control of follicular wave emergence in cattle. Theriogenology 43 31-40,

Bodensteiner KJ, Kot K, Wiltbank MC \& Ginther Ol 1996 Synchronization of emergence of follicular waves in cattle. Theriogenology 45 1115-1128.

Bridges GA, Helser LA, Grum DE, Mussard ML, Gasser CL \& Day ML 2008 Decreasing the interval between GnRH and PGF(2 alpha) from 7 to 5 days and lengthening proestrus increases timed-Al pregnancy rates in beef cows. Theriogenology 69 843-851.
Bridges GA, Mussard ML, Burke CR \& Day ML 2010 Influence of the length of proestrus on fertility and endocrine function in female cattle. Anim Reprod Sci 117 208-215.

Brusveen DJ, Cunha AP, Silva CD, Cunha PM, Sterry RA, Silva EPB, Guenther IN \& Wiltbank MC 2008 Altering the time of the second gonadotropin-releasing hormone injection and artificial insemination (Al) during ovsynch affects pregnancies per $\mathrm{Al}$ in lactating dairy cows. I Dairy Sci 91 1044-1052.

Brusveen DI, Souza AH \& Wiltbank MC 2009 Effects of additional prostaglandin F-2 alpha and estradiol-17 beta during Ovsynch in lactating dairy cows. I Dairy Sci $921412-1422$.

Burke CR, Mussard ML, Gasser CL, Grum DE \& Day ML 2003 Estradiol benzoate delays new follicular wave emergence in a dose-dependent manner after ablation of the dominant ovarian follicle in cattle. Theriogenology 60 647-658.

Butler ST, Pelton SH \& Butler WR 2006 Energy balance, metabolic status, and the first postpartum ovarian follicle wave in cows administered propylene glycol. I Dairy Sci 89 2938-2951.

Cavalieri J, Hepworth G, Parker KI, Wright PJ \& Macmillan KL 2003 Effect of treatment with progesterone and oestradiol when starting treatment with an intravaginal progesterone releasing insert on ovarian follicular development and hormonal concentrations in Holstein cows. Anim Reprod Sci 76 177-193.

Cerri RLA, Rutigliano HM, Chebel RC \& Santos JEP 2009 Period of dominance of the ovulatory follicle influences embryo quality in lactating dairy cows. Reproduction 137 813-823.

Cerri R LA, Santos JEP, Juchem SO, Galvao KN \& Chebel RC 2004 Timed artificial insemination with estradiol cypionate or insemination at estrus in high-producing dairy cows, I Dairy Sci 87 3704-3715.

Colazo MG, Kastelic JP, Martinez MF, Whittaker PR, Wilde R, Ambrose JD, Corbett R \& Mapletoft RJ 2004 Fertility following fixed-time AI in CIDR-treated beef heifers given GnRH or estradiol cypionate and fed diets supplemented with flax seed or sunflower seed. Theriogenology 61 1115-1124.

Colazo MG, Martinez MF, Small JA, Kastelic JP, Burnley CA, Ward DR \& Mapletoft RJ 2005 Effect of estradiol valerate on ovarian follicle dynamics and superovulatory response in progestin-treated cattle. Theriogenology 63 1454-1468.

Crowe MA 2008 Resumption of ovarian cyclicity in post-partum beef and dairy cows. Reprod Domest Anim 43 20-28.

De Rensis F, Lopez-Gatius F, Garcia-Ispierto I \& Techakumpu M 2010 Clinical use of human 
chorionic gonadotropin in dairy cows: An update. Theriogenology 73 1001-1008.

Diskin MG, Austin EJ \& Roche JF 2002 Exogenous hormonal manipulation of ovarian activity in cattle. Domest Anim Endocrin 23 211-228.

Ei-Zarkouny SZ, Cartmill JA, Hensley BA \& Stevenson JS 2004 Pregnancy in dairy cows after synchronized ovulation regimens with or without presynchronization and progesterone. / Dairy Sci 87 1024-1037.

Fonseca FA, Britt JH, Mcdaniel BT, Wilk JC \& Rakes AH 1983 Reproductive traits of Holsteins and Jerseys effects of age, milk-yield, and clinical abnormalities on involution of cervix and uterus, ovulation, estrous cycles, detection of estrus, conception rate, and days open. J Dairy Sci 66 1128-1147.

Galvao KN \& Santos JEP 2010 Factors affecting synchronization and conception rate after the Ovsynch protocol in lactating Holstein cows. Reprod Domest Anim 45 439-446.

Galvao KN, Santos JEP, Cerri RL, Chebel RC, Rutigliano HM, Bruno RG \& Bicalho RC 2007 Evaluation of methods of resynchronization for insemination in cows of unknown pregnancy status. I Dairy Sci 90 4240-4252.

Ginther OJ, Kot K, Kulick LJ, Martin S \& Wiltbank MC 1996a Relationships between FSH and ovarian follicular waves during the last six months of pregnancy in cattle. J Reprod Fertil 108 271-279.

Ginther OJ, Wiltbank MC, Fricke PM, Gibbons JR \& Kot K 1996b Selection of the dominant follicle in cattle. Biol Reprod 55 1187-1194.

Gumen A, Guenther JN \& Wiltbank MC 2003 Follicular size and response to Ovsynch versus detection of estrus in anovular and ovular lactating dairy cows. J Dairy Sci 86 3184-3194.

Gumen A \& Wiltbank MC 2002 An alteration in the hypothalamic action of estradiol due to lack of progesterone exposure can cause follicular cysts in cattle. Biol Reprod 66 1689-1695.

Gumen A \& Wiltbank MC 2005 Follicular cysts occur after a normal estradiol-induced GnRH/LH surge if the corpus hemorrhagicum is removed. Reproduction 129 737-745.

Kim UH, Suh GH, Hur TY, Kang SJ, Kang HG, Park SB, Kim HS \& Kim IH 2007a Comparison of two types of CIDR-based timed artificial insemination protocols for repeat breeder dairy cows. Journal of Reproduction and Development 53 639-645.

Kim UH, Suh GH, Hur TY, Kang SJ, Kang HG, Park SB, Kim HS \& Kim IH 2007b The effects of administering estradiol benzoate plus progesterone during the growth or static phases of the dominant follicle in CIDR-treated lactating dairy cows. Journal of Reproduction and Development 53 591-596.

Knopf L, Kastelic JP, Schallenberger E \& Ginther OJ 1989 Ovarian follicular dynamics in heifers - test of 2-wave hypothesis by ultrasonically monitoring individual follicles. Domest Anim Endocrin 6 111-119.

Lauderdale JW 2009 ASAS Centennial Paper: Contributions in the Journal of Animal Science to the development of protocols for breeding management of cattle through synchronization of estrus and ovulation. J Anim Sci 87 801-812.

Leroy ILMR, Opsomer G, Van Soom A, Goovaerts IGF \& Bols P 2008a Reduced fertility in high-yielding dairy cows: Are the oocyte and embryo in danger? Part I The importance of negative energy balance and altered corpus luteum function to the reduction of oocyte and embryo quality in high-yielding dairy cows. Reprod Domest Anim 43 612-622.

Leroy JLMR, Van Soom A, Opsomer G, Goovaerts IGF \& Bols PEJ 2008b Reduced fertility in high-yielding dairy cows: Are the oocyte and embryo in danger? Part II Mechanisms linking nutrition and reduced oocyte and embryo quality in high-yielding dairy cows. Reprod Domest Anim 43 623-632.

Lopez H, Caraviello DZ, Satter LD, Fricke PM \& Wiltbank MC 2005 Relationship between level of milk production and multiple ovulations in lactating dairy cows. J Dairy Sci $\mathbf{8 8}$ 2783-2793.

Lopez H, Sartori R \& Wiltbank MC 2005 Reproductive hormones and follicular growth during development of one or multiple dominant follicles in cattle. Biol Reprod 72 788-795.

Lopez H, Satter LD \& Wiltbank MC 2004 Relationship between level of milk production and estrous behavior of lactating dairy cows. Anim Reprod Sci 81 209-223.

Macmillan KL, Segwagwe BVE \& Pino CS 2003 Associations between the manipulation of patterns of follicular development and fertility in cattle. Anim Reprod Sci 78 327-344.

Mann GE, Fray MD \& Lamming GE 2006 Effects of time of progesterone supplementation on embryo development and interferon-tau production in the cow. Vet/171 500-503.

Martinez MF, Kastelic JP, Bo GA, Caccia M \& Mapletoft RJ 2005 Effects of oestradiol and some of its esters on gonadotrophin release and ovarian follicular dynamics in CIDR-treated beef cattle. Anim Reprod Sci 86 37-52.

Moreira F, de la Sota RL, Diaz T \& Thatcher WW 2000 Effect of day of the estrous cycle at the initiation of a timed artificial insemination protocol on reproductive responses in dairy heifers. I Anim Sci 78 1568-1576.

Moreira F, Orlandi C, Risco CA, Mattos R, Lopes F \& Thatcher WW 2001 Effects of presynchronization and bovine somatotropin on pregnancy rates to a timed artificial insemination protocol in lactating dairy cows. J Dairy Sci 84 1646-1659.

Odde K G 1990 A review of synchronization of estrus in postpartum cattle. J Anim Sci 68 817-830.

Pancarci SM, Jordan ER, Risco CA, Schouten MJ, Lopes FL, Moreira F \& Thatcher WW 2002 Use of estradiol cypionate in a presynchronized timed artificial insemination program for lactating dairy cattle. J Dairy Sci 85 122-131.

Pursley JR, Kosorok MR \& Wiltbank MC 1997 Reproductive management of lactating dairy cows using synchronization of ovulation. / Dairy Sci $\mathbf{8 0}$ 301-306.

Pursley JR, Mee MO \& Wiltbank MC 1995 Synchronization 
of ovulation in dairy cows using PGF(2-alpha) and GnRH. Theriogenology 44 915-923.

Rabiee AR, Lean IJ \& Stevenson MA 2005 Efficacy of Ovsynch program on reproductive performance in dairy cattle: A meta-analysis. J Dairy Sci 88 2754-2770.

Revah I \& Butler WR 1996 Prolonged dominance of follicles and reduced viability of bovine oocytes. I Reprod Fertil 106 39-47.

Rutigliano HM, Lima FS, Cerri RLA, Greco LF, Vilela JM, Magalhaes V, Silvestre FT, Thatcher WW \& Santos JEP 2008 Effects of method of presynchronization and source of selenium on uterine health and reproduction in dairy cows. J Dairy Sci 91 3323-3336.

Sangsritavong S, Combs DK, Sartori R, Armentano LE \& Wiltbank MC 2002 High feed intake increases liver blood flow and metabolism of progesterone and estradiol-17 beta in dairy cattle. J Dairy Sci $\mathbf{8 5}$ 2831-2842.

Santos JEP, Narciso CD, Rivera F, Thatcher WW \& Chebel RC 2010 Effect of reducing the period of follicle dominance in a timed artificial insemination protocol on reproduction of dairy cows. J Dairy Sci 93 2976-2988.

Santos JEP, Thatcher WW, Pool L \& Overton MW 2001 Effect of human chorionic gonadotropin, on luteal function and reproductive performance of highproducing lactating Holstein dairy cows. J Anim Sci 79 2881-2894.

Sartori R, Haughian JM, Shaver RD, Rosa GJM \& Wiltbank MC 2004 Comparison of ovarian function and circulating steroids in estrous cycles of Holstein heifers and lactating cows. J Dairy Sci 87 905-920.

Savio JD, Boland MP \& Roche JF 1990 Development of dominant follicles and length of ovarian cycles in postpartum dairy cows. J Reprod Fertil 88 581-591.

Savio JD, Keenan L, Boland MP \& Roche JF 1988 Pattern of growth of dominant follicles during the estrous cycle of heifers. J Reprod Fertil 83 663-671.

Silva E, Sterry RA, Kolb D, Wiltbank MC \& Fricke PM 2007 Effect of pretreatment with prostaglandin F-2 alpha before resynchronization of ovulation on fertility of lactating dairy cows. J Dairy Sci 90 5509-5517.

Sirois J \& Fortune JE 1988 Ovarian follicular dynamics during the estrous cycle in heifers monitored by realtime ultrasonography. Biol Reprod 39 308-317.

Souza AH, Ayres H, Ferreira RM \& Wiltbank MC 2008 A new presynchronization system (Double-Ovsynch) increases fertility at first postpartum timed $\mathrm{Al}$ in lactating dairy cows. Theriogenology 70 208-215.

Souza AH, Cunha AP, Caraviello DZ \& Wiltbank MC 2005 Profiles of circulating estradiol-17 beta after different estrogen treatments in lactating dairy cows. Animal Reproduction $2224-232$.

Souza AH, Gumen A, Silva EPB, Cunha AP, Guenther JN, Peto CM, Caraviello DZ \& Wiltbank MC 2007 Supplementation with estradiol-17 beta before the last gonadotropin-releasing hormone injection of the ovsynch protocol in lactating dairy cows. J Dairy Sci 90 4623-4634.

Souza AH, Viechnieski S, Lima FA, Silva FF, Araujo R,
Bo GA, Wiltbank MC \& Baruselli PS 2009 Effects of equine chorionic gonadotropin and type of ovulatory stimulus in a timed-Al protocol on reproductive responses in dairy cows. Theriogenology 72 10-21.

Stevenson JS, Tiffany SM \& Lucy MC 2004 Use of estradiol cypionate as a substitute for $\mathrm{GnRH}$ in protocols for synchronizing ovulation in dairy cattle. J Dairy Sci 87 3298-3305.

Stumpf TT, Roberson MS, Wolfe MW, Hamernik DL, Kittok RJ \& Kinder JE 1993 Progesterone, 17-betaestradiol, and opioid neuropeptides Modulate Pattern of Luteinizing-Hormone in Circulation of the Cow. Biol Reprod 49 1096-1101.

Thatcher WW, delaSota RL, Schmitt EJP, Diaz TC, Badinga L, Simmen FA, Staples CR \& Drost M 1996 Control and management of ovarian follicles in cattle to optimize fertility. Reprod Fert Develop 8 203-217.

Thatcher WW, Drost M, Savio JD, Macmillan KL, Entwistle KW, Schmitt EJ, Delasota RL \& Morris GR 1993 New Clinical Uses of Gnrh and Its Analogs in Cattle. Anim Reprod Sci 33 27-49.

Thatcher WW, Moreira F, Pancarci SM, Bartolome JA \& Santos JEP 2002 Strategies to optimize reproductive efficiency by regulation of ovarian function. Domest Anim Endocrin 23 243-254.

Thatcher WW, Santos JEP, Silvestre FT, Kim IH \& Staples CR 2010 Special Issue: 14th Annual Conference of the European Society for Domestic Animal Reproduction (ESDAR) Abstracts. Reprod Domest Anim 45 2-14.

Thundathil J, Kastelic JP \& Mapletoft RJ 1998 The effect of estradiol cypionate (ECP) on ovarian follicular development and ovulation in dairy cattle. Can J Anim Sci 62 314-316.

Townson DH, Tsang PCW, Butler WR, Frajblat $M$, Griel LC, Johnson CJ, Milvae RA, Niksic GM \& Pate JL 2002 Relationship of fertility to ovarian follicular waves before breeding in dairy cows. I Anim Sci $\mathbf{8 0}$ 1053-1058.

Vasconcelos J, Silcox R, Rosa G, Pursley JR \& Wiltbank MC 1999 Synchronization rate, size of the ovulatory follicle, and pregnancy rate after synchronization of ovulation beginning on different days of the estrous cycle in lactating dairy cows. Theriogenology 52 1067-1078.

Vasconcelos JLM, Sartori R, Oliveira HN, Guenther JN \& Wiltbank MC 2001 Reduction in size of the ovulatory follicle reduces subsequent luteal size and pregnancy rate. Theriogenology 56 307-314.

Wiltbank JN, Zimmerman DR, Ingalls JE \& Rowden WW 1965 Use of Progestational Compounds Alone or in Combination with Estrogen for Synchronization of Estrus. J Anim Sci 24 990-998.

Wiltbank M, Lopez H, Sartori R, Sangsritavong S \& Gumen A 2006 Changes in reproductive physiology of lactating dairy cows due to elevated steroid metabolism. Theriogenology 65 17-29.

Wiltbank MC, Guenther JN \& Fricke PM 2008a Resynchronization strategies in lactating dairy cows. Proceedings of the Dairy Cattle Reproduction Congress 9-16. 
Wiltbank MC, Gumen A, Lopez H \& Sartori R 2008b Management and treatment of dairy cows that are not cycling or have follicular cysts. Cattle Practice 16 14-19.

Wiltbank MC, Gumen A \& Sartori R 2002 Physiological classification of anovulatory conditions in cattle, Theriogenology 57 21-52.

Xu ZZ, Burton LJ \& Macmillan KL 1997 Reproductive performance of lactating dairy cows following estrus synchronization regimens with PGF2 alpha and progesterone. Theriogenology 47 687-701.

Zimbelman RG \& Smith LW 1966 Control of Ovulation in Cattle with Melengestrol Acetate .2. Effects on Follicular Size and Activity. I Reprod Fertil 11 193-201. 
